Review began 08/07/2021 Review ended 08/19/2021 Published 08/25/2021

๑) Copyright 2021 Koufopoulos et al. This is an open access article distributed under the terms of the Creative Commons Attribution License CCBY 4.0., which permits unrestricted use, distribution, and reproduction in any medium, provided the original author and source are credited.

\section{Gastrointestinal Stromal Tumor With Chondrosarcomatous Dedifferentiation Following Imatinib Therapy}

\author{
Nektarios Koufopoulos ${ }^{1}$, Andriani Zacharatou ${ }^{1}$, Sophia Athanasiadou ${ }^{2}$, Periklis Tomos ${ }^{3}$, Panagiota
} Ekonomopoulou $^{4}$, Theodoros Liakakos ${ }^{5}$, Ioannis G. Panayiotides ${ }^{1}$

1. 2nd Department of Pathology, National and Kapodistrian University of Athens, "Attikon" University Hospital, Athens, GRC 2. Department of Pathology, “Vardakeion and Proion” General Hospital of Syros, Hermoupolis, GRC 3. Department of Thoracic Surgery, National and Kapodistrian University of Athens, "Attikon" University Hospital, Athens, GRC 4. 2nd Department of Internal Medicine - Propaedeutic, National and Kapodistrian University of Athens, "Attikon" University Hospital, Athens, GRC 5. 1st Department of Surgery, "Laikon" General University Hospital/National and Kapodistrian University of Athens, School of Medicine, Athens, GRC

Corresponding author: Nektarios Koufopoulos, koufonektar@yahoo.com

\begin{abstract}
Gastrointestinal stromal tumors (GISTs) are the most common mesenchymal neoplasms of the digestive tract, followed by schwannomas, lipomas, leiomyomas, and vascular tumors. They arise more often in the stomach, followed by the small bowel, esophagus, and rectum. Imatinib mesylate, a tyrosine kinase inhibitor with activity against ABL, BCR-ABL, platelet-derived growth factor receptor-alpha (PDGFRA), and c-KIT (CD117), constitutes the cornerstone of treatment for inoperable or metastatic GIST. Cases showing disease progression or resistance to imatinib mesylate may retain their morphology or present unusual morphologic and immunohistochemical characteristics.
\end{abstract}

We herein describe a case of a 67-year-old patient with a previous history of GIST of the stomach, with local recurrence, who was admitted with a workup of lung nodule on chest computed tomography as part of the routine follow-up. The nodule was resected which showed a malignant tumor composed of epithelioid cells, with an abrupt transition to chondrosarcoma. Epithelioid cells were immunostained for CD117, DOG1, and Vimentin, whereas chondrosarcomatous cells expressed only Vimentin. These findings were consistent with metachronous pulmonary metastasis of the previously diagnosed GIST with chondrosarcomatous dedifferentiation. No KIT or PDGFRA mutation was detected. A review of all accessible pertinent papers disclosed 26 similar cases with unusual morphological and immunohistochemical findings, either postimatinib treatment or, less commonly, de novo, with heterogeneous differentiation.

Awareness of the histological and immunohistochemical changes in GISTs post imatinib therapy is essential to avoid a severe diagnostic pitfall.

Categories: Pathology, General Surgery, Oncology

Keywords: gastrointestinal stromal tumor, dedifferentiation, stomach, cd117, metastasis, imatinib

\section{Introduction}

Gastrointestinal stromal tumors (GISTs) are the most common mesenchymal tumors of the digestive tract. They originate from or differentiate into interstitial cells of Cajal, which function as pacemaker cells [1]. They usually arise from the stomach, followed by the small bowel, esophagus, and rectum [2]; less often, GISTs have been reported in the gallbladder and appendix [1]. Moreover, so-called extra-gastrointestinal GISTs (E-GISTs) have been reported in the prostate, mesentery, omentum, retroperitoneum, scrotum, bladder, ovary, pancreas, and vagina [3]. Imatinib mesylate (IM), an oral tyrosine kinase inhibitor (TKI) targeting c-KIT (CD117), platelet-derived growth factor receptor-alpha (PDGFRA), and the fusion protein BCR-ABL [3] constitutes first-line standard treatment for locally advanced or metastatic GISTs. Patients with GIST treated with IM show a remarkable initial benefit followed, in the majority of patients, by disease progression or secondary resistance due to acquired mutations in c-KIT or PDGFRA [4]. Disease progression is manifested as general tumor expansion, resistant nodules, or new metastatic lesions $[5,6]$. The majority of tumors during disease progression retain their original morphological features, while in a few cases they may develop heterogeneous differentiation [7].

Post-IM treatment dedifferentiation of a spindle cell GIST, demonstrating an abrupt transition to a highgrade sarcoma with loss of CD117 and CD34 expression in the dedifferentiated component, was first described by Pauwels et al. in 2005 [5]; in 2013, Antonescu et al. described de novo GIST dedifferentiation in TKI naïve tumors [8]. Twenty-six cases of dedifferentiated GIST have so far been described [5-16], displaying a wide morphologic and immunophenotypic spectrum of dedifferentiation. 


\section{Cureus}

heterologous differentiation after therapy with IM; our case is the first (to our best knowledge) with chondrosarcomatous histology, thus adding another morphologic facet to GIST dedifferentiation.

\section{Case Presentation}

A 67-year-old male was admitted to the Department of Thoracic Surgery in July 2019. Past medical history was significant for a previously (2005) operated, $10 \mathrm{~cm}$ large gastric GIST with metastasis to two regional lymph nodes. The patient received adjuvant therapy with IM for 24 months. Surgical resection of a recurrent tumor was performed in 2009, with a further 12-month adjuvant treatment with IM. His clinical course was uneventful until 2018 when a small lesion adjacent to the tail of the pancreas was found on abdominal computed tomography (CT). This lesion was stable until 2019 when a $1 \mathrm{~cm}$ tumor was found in the left lung's lower lobe on chest CT, consistent with either metastasis or a second primary (Figures 1A, 1B). Wedge resection of the lung tumor was performed.
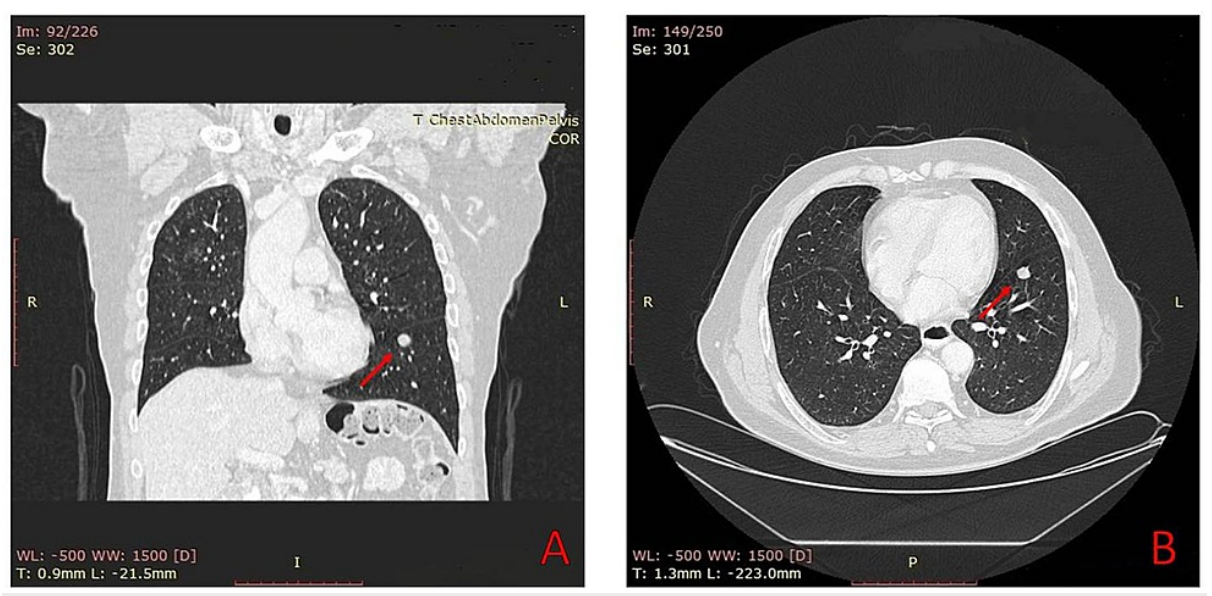

\section{FIGURE 1: Chest CT revealed a $1 \mathrm{~cm}$ lesion in the lower lobe of the left lung (red arrows).}

The resection specimen was fixed in $10 \%$ buffered formalin for 24 hours. On gross examination, a wellcircumscribed, solid, gray-white, 1.3-cm-large tumor was found; it was embedded in toto. Both hematoxylin and eosin (H\&E) stained and immunostained sections from the previously operated gastric tumor were retrieved from the files of the Department of Pathology and compared to those of the lung tumor. This consisted of two components: an epithelioid one, with a solid architecture, high-grade atypia, and numerous mitotic figures, with an abrupt transition to an atypical chondrogenic component, consistent with chondrosarcoma (Figures $2 \mathrm{~A}-2 \mathrm{C}$ ). Thus, whereas the primary gastric tumor was a spindle-cell GIST, the recurrent tumor had both an epithelioid and a chondrosarcomatous component. The epithelioid component expressed DOG-1 (Figure 2D) and CD117 (Figure 2E), whereas both components were immunostained for Vimentin (Figure 2F); CKAE1/AE3, CK5/6, p63, TTF1, Napsin A, and CD99 immunostains were uniformly negative. Analysis through immunostains performed at the initial diagnosis showed both the primary gastric tumor and the recurrence to be positive for CD117, CD34, and Vimentin and negative for CKAE1/AE3 SMA, Desmin, and S100 protein. A diagnosis of a malignant pulmonary neoplasm with morphological and immunohistochemical features consistent with metastasis of the previously diagnosed gastric GIST, with heterologous chondrosarcomatous dedifferentiation, was rendered. 


\section{Cureus}
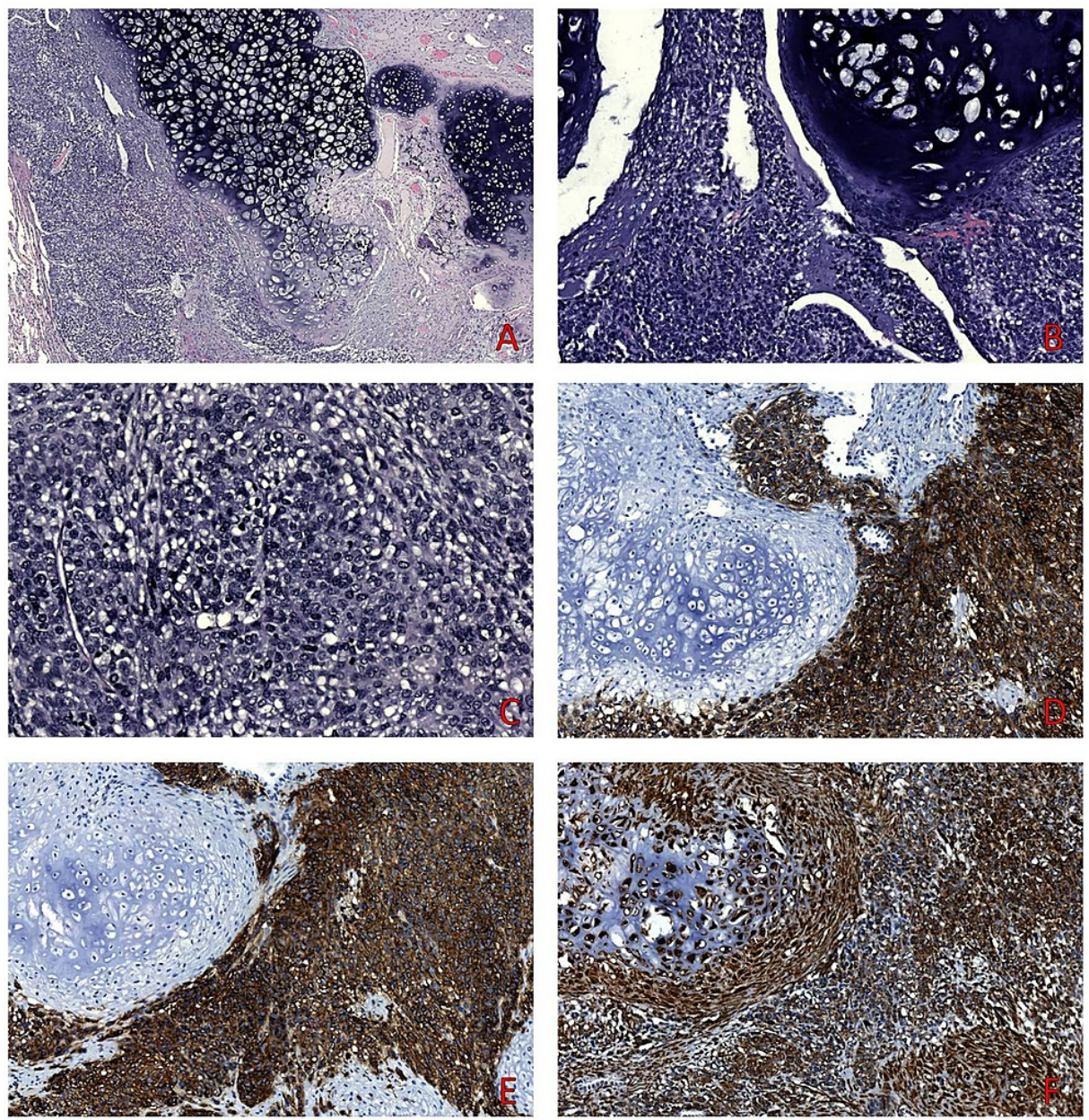

FIGURE 2: The lung metastasis showed a biphasic appearance

consisting of epithelioid and chondrosarcomatous components (A-C).

Epithelioid areas stained diffusely for DOG1 (D) and CD117 (E), while

Vimentin showed uniform staining in all tumors cells $(F)$.

Mutational analysis with real-time PCR technique was performed on samples from the primary tumor, the local recurrence, and both differentiated and dedifferentiated areas of the pulmonary tumor, revealing no KIT or PDGFRA mutation. IM treatment was resumed. Four months later, abdominal CT showed a decrease in the size of the juxtapancreatic tumor. The patient is currently still on IM.

\section{Discussion}

GISTs are the commonest mesenchymal tumors of the digestive tract, usually displaying spindle cell morphology, with epithelioid or mixed patterns being less frequent. All subtypes have uniform nuclei and usually display low mitotic activity [1].

Immunostaining for CD117, DOG1, and CD34 clinches the diagnosis of GIST; CD117 stains ca 95\% of tumors, DOG1 75\%-100\%, and CD34 60\%-70\% of tumors [1]. Neoplastic cells may less often be decorated for SMA, S100 protein, desmin, or keratin [17].

Most GISTs have KIT gene mutations, most commonly located in exon 11 and less often in exons 9, 13, or 17 [18-20]. PDGFRA gene mutations occur less frequently (10\%-15\% of GISTs) involving exons 12, 14, or 18 [21]. KRAS mutations have been reported in $5 \%$ of GISTs and may be related to a possible novel mechanism of primary resistance to IM [22]. Wild type KIT/PDGFRA/RAS GISTs may harbor succinate dehydrogenase deficiencies [23] or BRAF exon 15 V600E mutations [24,25].

Few cases of GIST dedifferentiation have previously been reported: a review of the pertinent English literature yielded 12 papers describing 26 cases with unusual morphological and/or immunohistochemical findings, either de novo or after therapy with TKIs [5-16]. Four papers described eight, five, three, and two cases, respectively, whereas the remaining eight were single case reports. Patient ages ranged from 23 to 75 


\section{Cureus}

years (median 55 years); 20 patients were male and six female. The primary tumor was located in the stomach (15 cases), small bowel (seven cases), colon (two cases), and rectum (one case), with a single retroperitoneal E-GIST. Demographic and clinicopathological data of all cases are summarized in Table 1.

\begin{tabular}{|c|c|c|c|c|c|c|c|c|c|}
\hline Case & Author & Year & Age & Sex & $\begin{array}{l}\text { Tumor } \\
\text { size }\end{array}$ & Tumor location & $\begin{array}{l}\text { Metastases at } \\
\text { presentation }\end{array}$ & LR/ Metachronous Metastases & $\begin{array}{l}\text { Outcome } \\
\text { (mo) }\end{array}$ \\
\hline 1 & $\begin{array}{l}\text { Pauwels et } \\
\text { al. [5] }\end{array}$ & 2005 & 37 & $\mathrm{M}$ & NA & Stomach & No & Abdominal, disseminated & DOD \\
\hline 2 & $\begin{array}{l}\text { Pauwels et } \\
\text { al. [5] }\end{array}$ & 2005 & 46 & $\mathrm{M}$ & $17 \mathrm{~cm}$ & Small bowel & No & Liver & ANED 31 \\
\hline 3 & $\begin{array}{l}\text { Pauwels et } \\
\text { al. [5] }\end{array}$ & 2005 & 73 & $\mathrm{M}$ & $7.5 \mathrm{~cm}$ & Rectum & No & Liver, peritoneum & AWD 88 \\
\hline 4 & $\begin{array}{l}\text { Liegl et al. } \\
\text { [9] }\end{array}$ & 2009 & 53 & $\mathrm{M}$ & $15 \mathrm{~cm}$ & Small bowel & No & Liver, abdominal & DOD 87 \\
\hline 5 & $\begin{array}{l}\text { Liegl et al. } \\
\text { [9] }\end{array}$ & 2009 & 39 & $\mathrm{~F}$ & $6 \mathrm{~cm}$ & Small bowel & Liver, pancreas & $\begin{array}{l}\text { Peritoneal, retroperitoneal, right ovary, left lung, } \\
\text { para-aortic LNs, L1 vertebral body }\end{array}$ & DOD 22 \\
\hline 6 & $\begin{array}{l}\text { Liegl et al. } \\
\text { [9] }\end{array}$ & 2009 & 35 & $\mathrm{~F}$ & $10 \mathrm{~cm}$ & Stomach & No & Abdominal, pelvic & AWD 65 \\
\hline 7 & $\begin{array}{l}\text { Liegl et } \\
\text { al. [9] }\end{array}$ & 2009 & 57 & $\mathrm{M}$ & $16 \mathrm{~cm}$ & Stomach & No & Abdominal & AWD 33 \\
\hline 8 & $\begin{array}{l}\text { Liegl et } \\
\text { al. [9] }\end{array}$ & 2009 & 66 & $\mathrm{M}$ & $20 \mathrm{~cm}$ & Stomach & No & Peritoneal & ANED 33 \\
\hline 9 & $\begin{array}{l}\text { Vassos et } \\
\text { al. [10] }\end{array}$ & 2011 & 62 & $\mathrm{~F}$ & $20 \mathrm{~cm}$ & Stomach & No & No & ANED 28 \\
\hline 10 & $\begin{array}{l}\text { Martz et al. } \\
{[11]}\end{array}$ & 2013 & 65 & $\mathrm{M}$ & $13 \mathrm{~cm}$ & Small bowel $\left.\right|^{\star \star}$ & $\begin{array}{l}\text { Retroperitoneal } \\
\text { LNs }\end{array}$ & Liver, omental, LNs & NM \\
\hline 11 & $\begin{array}{l}\text { Antonescu } \\
\text { et al. [8] }\end{array}$ & 2013 & 23 & $\mathrm{M}$ & NA & Stomach & Liver & Liver, peritoneal & NM \\
\hline 12 & $\begin{array}{l}\text { Antonescu } \\
\text { et al. [8] }\end{array}$ & 2013 & 40 & $\mathrm{~F}$ & $8 \mathrm{~cm}$ & Stomach* & Peritoneum & Peritoneal & NM \\
\hline 13 & $\begin{array}{l}\text { Antonescu } \\
\text { et al. [8] }\end{array}$ & 2013 & 55 & $\mathrm{M}$ & $18 \mathrm{~cm}$ & Stomach* & No & No & NM \\
\hline 14 & $\begin{array}{l}\text { Antonescu } \\
\text { et al. [8] }\end{array}$ & 2013 & 48 & $\mathrm{M}$ & $5.5 \mathrm{~cm}$ & Stomach* & Peritoneum & Liver, peritoneal & NM \\
\hline 15 & $\begin{array}{l}\text { Antonescu } \\
\text { et al. [8] }\end{array}$ & 2013 & 58 & $\mathrm{M}$ & $6 \mathrm{~cm}$ & Rectum* & No & No & NM \\
\hline 16 & $\begin{array}{l}\text { Antonescu } \\
\text { et al. [8] }\end{array}$ & 2013 & 53 & $\mathrm{M}$ & $7 \mathrm{~cm}$ & Stomach* & $\begin{array}{l}\text { Locoregional } \\
\text { LNs }\end{array}$ & Peritoneal & NM \\
\hline 17 & $\begin{array}{l}\text { Antonescu } \\
\text { et al. [8] }\end{array}$ & 2013 & 60 & $\mathrm{M}$ & $7.5 \mathrm{~cm}$ & Small bowel & No & Liver, peritoneal & NM \\
\hline 18 & $\begin{array}{l}\text { Antonescu } \\
\text { et al. [8] }\end{array}$ & 2013 & 65 & $\mathrm{M}$ & $25 \mathrm{~cm}$ & Colon & No & Peritoneal & NM \\
\hline 19 & $\begin{array}{l}\text { Jung et al. } \\
\text { [12] }\end{array}$ & 2013 & 51 & $\mathrm{M}$ & $11 \mathrm{~cm}$ & Stomach* & $\begin{array}{l}\text { Locoregional } \\
\text { LNs, liver }\end{array}$ & No & ANED 10 \\
\hline 20 & $\begin{array}{l}\text { Choi et al. } \\
{[13]}\end{array}$ & 2014 & 52 & $\mathrm{~F}$ & $30 \mathrm{~cm}$ & Small bowel ${ }^{\star}$ & No & No & NM \\
\hline 21 & $\begin{array}{l}\text { Jiang et al. } \\
\text { [6] }\end{array}$ & 2015 & 47 & $\mathrm{M}$ & $14 \mathrm{~cm}$ & Stomach & Pelvis & Pelvic & AWD 48 \\
\hline 22 & $\begin{array}{l}\text { Zhu et al. } \\
{[7]}\end{array}$ & 2015 & 57 & M & $12 \mathrm{~cm}$ & Retroperitoneum & No & LR after 15 mo & DOD 42 \\
\hline
\end{tabular}




\section{Cureus}

\begin{tabular}{|c|c|c|c|c|c|c|c|c|c|}
\hline 23 & $\begin{array}{l}\text { Jung et al. } \\
\text { [14] }\end{array}$ & 2017 & 72 & M & $7 \mathrm{~cm}$ & Stomach & Liver & Liver & AWD 72 \\
\hline 24 & $\begin{array}{l}\text { Jung et al. } \\
\text { [14] }\end{array}$ & 2017 & 67 & $\mathrm{~F}$ & $10 \mathrm{~cm}$ & Stomach & No & No & ANED 58 \\
\hline 25 & Li et al. [15] & 2019 & 75 & M & $9.3 \mathrm{~cm}$ & Stomach & No & No & ANED 20 \\
\hline 26 & $\begin{array}{l}\text { Shah et al. } \\
\text { [16] }\end{array}$ & 2021 & 64 & M & $8 \mathrm{~cm}$ & Small bowel * & No & NM & NM \\
\hline 27 & $\begin{array}{l}\text { Present } \\
\text { case }\end{array}$ & 2021 & 52 & M & $10 \mathrm{~cm}$ & Stomach & $\begin{array}{l}\text { Locoregional } \\
\text { LNs }\end{array}$ & LR after $60 \mathrm{mo}$, lung & $\begin{array}{l}\text { AWD } \\
190\end{array}$ \\
\hline
\end{tabular}

\section{TABLE 1: Demographic and clinical data of dedifferentiated GISTs}

M: male, F: female, LNs: lymph nodes, LR: local recurrence, NA: not available, NM: not mentioned, DOD: died of disease, AWD: alive with disease, ANED: Alive with no evidence of disease, mo: months, ${ }^{*}$ tumors with de novo dedifferentiation, ${ }^{*}$ previous IM treatment for chronic myeloid leukemia.

Pretreatment specimens were available in 18 cases: 16 had spindle-cell and the remaining two epithelioid morphology. The post-treatment aspect showed a well-differentiated spindle cell proliferation consistent with GIST next to a dedifferentiated high-grade malignancy, most frequently rhabdomyosarcomatous (eight cases) $[6,9,15,16]$, with six cases showing epithelioid/pleomorphic differentiation $[5,10,13]$, five cases nondescript anaplastic features [8] and one each showing epithelioid/tubulopapillary [5], undifferentiated pleomorphic sarcoma [12], and angiosarcomatous [8] features. The retroperitoneal E-GIST showed rhabdomyosarcomatous and chondrosarcomatous differentiation [7], whereas two cases showed changes in the immunophenotype without corresponding morphological alterations [14]. A case that deserves separate mention presented initially as a high-grade sarcoma of the small bowel, following long-term treatment with IM for chronic myeloid leukemia [11]. The diagnosis was confirmed by the molecular demonstration of a KIT exon 11 WK557-8 deletion [8].

In cases with available pretreatment samples, tumors showed almost always positive staining for CD117 and DOG1 and less often for CD34. In post-treatment tumors, the aforementioned markers were usually expressed in areas with GIST morphology and were lost or only focally retained in the dedifferentiated component. The expression of immunohistochemical markers in de novo dedifferentiated GISTs was similar to the post-treatment samples.

The case presented by Martz et al. showed strong diffuse staining for Vimentin, scattered positivity for CD34 and CAM5.2, MNF116, and multifocal positivity for EMA, CD117, DOG1, INI-1, ERG, and desmin. Lymphoid and melanoma markers were negative.

Regarding molecular findings, the three IM-resistant cases presented by Pauwels et al. had KIT exon 11 mutations [5]. In GISTs with rhabdomyoblastic differentiation, KIT exon 11 deletions [9], KIT exon 11 point mutation $[6,9,15]$, and PDGFR exon 18 deletions [9] were detected in both components, without secondary mutations in the dedifferentiated component $[9,14]$.

The molecular mechanism of tumor progression was investigated in three IM-treated and five IM-naïve tumors in the case series presented by Antonescu et al. [8]. Four of them had wild-type KIT, PDGFRA, and BRAF genes in both conventional and dedifferentiated components. Loss of a KIT gene copy due to haploinsufficiency was found in the dedifferentiated components of the three KIT-negative imatinibresistant GISTs. KIT mutations in exons 11 were present in the two cases described by Jung et al. [14]. KIT mutations in exons 11 and 13 were present in two IM-treated tumors. Loss of heterozygosity or low-level KIT amplification was the most common finding in the dedifferentiated components [8]. KIT and KRAS mutations were found in the CD117, DOG1, and CD34 negative GIST with anaplastic dedifferentiation presented by Martz et al. [11].

Seven tumors with de novo dedifferentiation have been described $[8,12,13]$. Antonescu et al. found KIT mutations on exon 11 in three out of five cases. The other two tumors were wild-type with lower levels of KIT amplification as compared to that of the KIT-positive component with classic GIST morphology. KIT exon 11 mutation was detected in the case reported by Jung et al. [12]. GISTs of the small intestine reported by Choi et al. and Shah et al. were wild type $[13,16]$.

The above findings suggest that dedifferentiation with loss of KIT expression may not be related to additional mutations in the original driver oncogene; dedifferentiation could result from alternative escape mechanisms driven by KIT-independent signaling pathways [1]. 
Follow-up information was available in 15 cases, ranging from 10 to 87 months. Six patients were alive with no evidence of disease, five were alive with disease, and four died of the disease.

GIST dedifferentiation might cause diagnostic problems for the inexperienced pathologist. Malignant "Triton" tumor, dedifferentiated liposarcoma, desmoid fibromatosis, or collision tumors are significant diagnostic problems. In difficult or doubtful cases, extensive sampling, detailed morphological analysis, appropriate use of immunohistochemical markers, and mutational analysis are the key to the correct diagnosis.

In our case, due to the biphasic (epithelioid and chondrosarcomatous) morphology, the differential diagnosis included sarcomatoid carcinoma of the lung; immunopositivity of neoplastic cells for CD117, DOG1, and negative staining for epithelial markers as well as for TTF1, Napsin A, and p63 resolved the diagnostic problem.

\section{Conclusions}

We herein present the first (to our best knowledge) case of dedifferentiated GIST with heterologous, chondrosarcomatous differentiation, after treatment with IM. Awareness of the histological and immunohistochemical changes in GISTs, usually post-IM treatment, is essential to avoid severe diagnostic pitfalls. Furthermore, precise early diagnosis of dedifferentiation will lead to correct therapeutic decisions.

\section{Additional Information}

\section{Disclosures}

Human subjects: Consent was obtained or waived by all participants in this study. Conflicts of interest: In compliance with the ICMJE uniform disclosure form, all authors declare the following: Payment/services info: All authors have declared that no financial support was received from any organization for the submitted work. Financial relationships: All authors have declared that they have no financial relationships at present or within the previous three years with any organizations that might have an interest in the submitted work. Other relationships: All authors have declared that there are no other relationships or activities that could appear to have influenced the submitted work.

\section{References}

1. Karakas C, Christensen P, Baek D, Jung M, Ro JY: Dedifferentiated gastrointestinal stromal tumor: recent advances. Ann Diagn Pathol. 2019, 39:118-24. 10.1016/j.anndiagpath.2018.12.005

2. Katz SC, DeMatteo RP: Gastrointestinal stromal tumors and leiomyosarcomas. J Surg Oncol. 2008, 97:350-9. 10.1002/jso.20970

3. You YH, Zhang Y: Primary prostatic extragastrointestinal stromal tumor: a case report and literature review . J Int Med Res. 2018, 46:4343-9. 10.1177/0300060518791677

4. Heinrich MC, Maki RG, Corless CL, et al.: Primary and secondary kinase genotypes correlate with the biological and clinical activity of sunitinib in imatinib-resistant gastrointestinal stromal tumor. J Clin Oncol. 2008, 26:5352-9. 10.1200/JCO.2007.15.7461

5. Pauwels P, Debiec-Rychter M, Stul M, De Wever I, Van Oosterom AT, Sciot R: Changing phenotype of gastrointestinal stromal tumours under imatinib mesylate treatment: a potential diagnostic pitfall. Histopathology. 2005, 47:41-7. 10.1111/j.1365-2559.2005.02179.x

6. Jiang X, Anderson HB, Guy CD, Mosca PI, Riedel RF, Cardona DM: Rhabdomyosarcomatous transformation of a gastrointestinal stromal tumor following treatment with iImatinib. Case Rep Oncol Med. 2015, 2015:317493. 10.1155/2015/317493

7. Zhu P, Fei Y, Wang Y, Ao Q, Wang G: Recurrent retroperitoneal extra-GIST with rhabdomyosarcomatous and chondrosarcomatous differentiations: a rare case and literature review. Int J Clin Exp Pathol. 2015, 8:9655-61.

8. Antonescu CR, Romeo S, Zhang L, et al.: Dedifferentiation in gastrointestinal stromal tumor to an anaplastic KIT-negative phenotype: a diagnostic pitfall: morphologic and molecular characterization of 8 cases occurring either de novo or after imatinib therapy. Am J Surg Pathol. 2013, 37:385-92. 10.1097/PAS.0b013e31826c1761

9. Liegl B, Hornick JL, Antonescu CR, Corless CL, Fletcher CD: Rhabdomyosarcomatous differentiation in gastrointestinal stromal tumors after tyrosine kinase inhibitor therapy: a novel form of tumor progression. Am J Surg Pathol. 2009, 33:218-26. 10.1097/PAS.0b013e31817ec2e6

10. Vassos N, Agaimy A, Schlabrakowski A, Hohenberger W, Schneider-Stock R, Croner RS: An unusual and potentially misleading phenotypic change in a primary gastrointestinal stromal tumour (GIST) under imatinib mesylate therapy. Virchows Arch. 2011, 458:363-9. 10.1007/s00428-010-1034-1

11. Martz J, Jain S, Vahdat LT, Qin L, Mosquera JM, Antonescu CR, Popa EC: High-grade KIT-negative sarcoma of the small bowel in a patient with chronic myeloid leukemia receiving long-term tyrosine kinase inhibitors. J Clin Oncol. 2013, 31:e181-5. 10.1200/JCO.2012.42.7989

12. Jung JH, Im S, Choi HJ, Lee YS, Jung ES: Gastrointestinal stromal tumor with dedifferentiation to undifferentiated pleomorphic sarcoma. Pathol Int. 2013, 63:479-82. 10.1111/pin.12095

13. Choi JJ, Sinada-Bottros L, Maker AV, Weisenberg E: Dedifferentiated gastrointestinal stromal tumor arising de novo from the small intestine. Pathol Res Pract. 2014, 210:264-6. 10.1016/j.prp.2013.12.008

14. Jung M, Park SH, Jeon YK, Won JK, Yang HK, Kim WH: Gastrointestinal stromal tumor of unusual phenotype after imatinib treatment: a case report and diagnostic utility of ETV1 mRNA in situ 


\section{Cureus}

hybridization. Medicine (Baltimore). 2017, 96:e9031. 10.1097/MD.0000000000009031

15. Li L, Khalili M, Johannes G, et al.: Case report of rhabdomyosarcomatous transformation of a primary gastrointestinal stromal tumor (GIST). BMC Cancer. 2019, 19:913. 10.1186/s12885-019-6085-3

16. Shah PA, Babu R, Uthaiah SB, Patil S: Rare case of a duodenal de novo dedifferentiated gastrointestinal stromal tumour. BMJ Case Rep. 2021, 14:e241442. 10.1136/bcr-2020-241442

17. Fletcher CD, Berman JJ, Corless C, et al.: Diagnosis of gastrointestinal stromal tumors: a consensus approach. Hum Pathol. 2002, 33:459-65. 10.1053/hupa.2002.123545

18. Hirota S, Isozaki K, Moriyama Y, et al.: Gain-of-function mutations of c-kit in human gastrointestinal stromal tumors. Science. 1998, 279:577-80. 10.1126/science.279.5350.577

19. Corless CL, Fletcher JA, Heinrich MC: Biology of gastrointestinal stromal tumors. J Clin Oncol. 2004, 22:3813-25. 10.1200/JCO.2004.05.140

20. Xu Z, Huo X, Tang C, et al.: Frequent KIT mutations in human gastrointestinal stromal tumors. Sci Rep. 2014, 4:5907. 10.1038/srep05907

21. Xu CW, Lin S, Wang WL, et al.: Analysis of mutation of the c-Kit gene and PDGFRA in gastrointestinal stromal tumors. Exp Ther Med. 2015, 10:1045-51. 10.3892/etm.2015.2613

22. Miranda C, Nucifora M, Molinari F, et al.: KRAS and BRAF mutations predict primary resistance to imatinib in gastrointestinal stromal tumors. Clin Cancer Res. 2012, 18:1769-76. 10.1158/1078-0432.CCR-11-2230

23. Rutter J, Winge DR, Schiffman JD: Succinate dehydrogenase - Assembly, regulation and role in human disease. Mitochondrion. 2010, 10:393-401. 10.1016/j.mito.2010.03.001

24. Hostein I, Faur N, Primois C, et al.: BRAF mutation status in gastrointestinal stromal tumors. Am J Clin Pathol. 2010, 133:141-8. 10.1309/AICPPCKGA2OGBJ1R

25. Agaimy A, Terracciano LM, Dirnhofer S, Tornillo L, Foerster A, Hartmann A, Bihl MP: V600E BRAF mutations are alternative early molecular events in a subset of KIT/PDGFRA wild-type gastrointestinal stromal tumours. J Clin Pathol. 2009, 62:613-6. 10.1136/jcp.2009.064550 